\title{
PSYCHOLOGICAL RESPONSES, COPING STRATEGIES, AND PHYSICAL ACTIVITY DURING THE COVID - 19 PANDEMIC: BULGARIAN PERSPECTIVE
}

\author{
Zornitza P. Mladenova
}

The Foundation for Global Community Health

\begin{abstract}
Nowadays our global society faces big challenges and threats in the times of the first major pandemic. The outbreak of COVID-19 has forced governments to impose the lock-down policies around the world. Social isolation became a new normal form of living. After the first confirmed case on the 8th of March in Bulgaria, the government announced on the 14th of March the lock-down as a preventive strategy for the whole Bulgarian population. Under such circumstances, the big issue became the question of how to maintain the physical and mental

health of people, and how to cope with the new reality. Based on this evidence the aim of the joint research study with Ohio State University, USA, entitled "Psychological Responses, Coping Strategies, and Physical Activity during the COVID - 19 Pandemic" has been proposed from the Bulgarian perspective as follows:

1. Investigate psychological responses, coping strategies, and physical activity during the COVID - 19 lock-down periods.

2. Examine the influence of physical activity as a coping strategy in psychological health and overall well-being during social isolation.

To this end, an online questionnaire containing an adapted version of the short-form of International Physical Activity Questionnaire (IPAQ-SF) has been used to assess the practiced level of physical activity and Metabolic Equivalents (MET) energy expenditure, PROMIS Item Bank v1.0 Emotional distress-Anxiety, Herth Hope Index (HHI) (Herth, 1992), and Brief Resilient Coping Scale BRCS (Sinclaire, Wallston, 2004) to evaluate psychological well-being during the social isolation.

Evidence suggests that regular participation in physical activity helps decrease overall levels of anxiety and depression as a reliable coping strategy to overcome the social isolation and, as a whole, the negative aspects of lockdown.
\end{abstract}

OPEN ACCESS

Submitted: 8 October 2020 Revised: 15 February 2021 Accepted: 18 February 2021

ORCID (iD)

Zornitza Mladenova https://orcid.org/ 0000-0002-1776-4600

Cite this article as: Mladenova, Z. (2021). Psychological responses, coping strategies, and physical activity during the COVID - 19 pandemic: Bulgarian perspective Journal of Applied Sports Sciences, Vol.1, pp. $93-105$. DOI: $10.37393 / J A S S .2021 .01 .8$

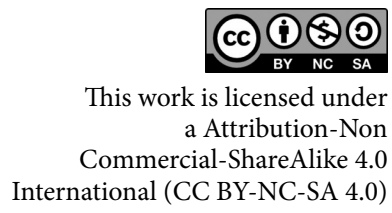

This work is licensed under a Attribution-Non Commercial-ShareAlike 4.0 International (CC BY-NC-SA 4.0)

Key words: COVID-19, physical and mental health, coping strategies

\section{INTRODUCTION}

The lock-down strategy against COVID-19 Pandemic was imposed in Bulgaria on the 13th of March. To ensure social distancing and limit the movement of the population, schools, public places, and businesses were shutdowns. Moreover, people could move away from their homes only to do essential work (healthcare and social care sectors, police, and armed forces, firefighting, water, and electricity supply) or perform essential activities (health visits, medicine purchases, or food supply). The worldwide spread of COVID-19 has upset the normality of daily life, forcing the population to social distancing and self-isolation. Since the containment precautions also concern sport-related activities, home workout remained the only possibility to play sports and stay active during the pandemic (Maugeri et al., 2020). Banned outdoor recreation, fear of being infected SARS-COV-2, and concerns of impact of this disease might be the reasons leading to a higher proportion of anxiety/depression (Tran et al., 2020). In addition 
to being a public physical health emergency, Coronavirus disease 2019 (COVID-19) affected global mental health, as evidenced by panic-buying worldwide as cases soared (Wang et al., 2020). Female gender; youth age; single status; students; specific symptoms; recent imposed quarantine; prolonged home-stay; and reports of poor health status, unnecessary worry, concerns for family members, and discrimination were significantly associated with greater psychological impact of the pandemic and higher levels of stress, anxiety and depression (Tee et al., 2020).

\section{Physical activity and overall health}

During the COVID-19 pandemic the necessity of urgent psychological intervention is becoming much more critical (Iancheva et al., 2020). The analysis of scientific publications shows a strong correlation between mental health and physical activity.

Most comorbid associations of depressive symptoms with specific chronic illnesses are explained by accompanying poor self-reported health and functional status, but some illnesses probably have a direct psychobiological basis (Niti et al., 2007). Many meta-analytical studies suggested a positive anxiolytic and depression-reducing effect of exercise programs (Wegner et al., 2014).

The prevalence of depression may be affected by changes in psychiatric practices and the availability of online mental health information in the past two decades (Lim, et al., 2018). There is now compelling evidence that a range of lifestyle factors are involved in the pathogenesis of depression. Many of these factors can potentially be modified, yet they receive little consideration in the contemporary treatment of depression, where medication and psychological intervention remain the first-line treatments. "Lifestyle Medicine" provides a nexus between public health pro- motion and clinical treatments, involving the application of environmental, behavioral, and psychological principles to enhance physical and mental wellbeing. This may also provide opportunities for general health promotion and potential prevention of depression (Sarris et al., 2014).

The benefits of physical activity - improving physical condition and fighting disease - have long been established. Physical activity is also considered vital for maintaining mental fitness and has been recognized as an effective coping strategy to deal with stress. Studies show that physical activity produces endorphins - a chemical in the brain that acts as natural painkillers - and also improves the ability to sleep, which in turn reduces stress. Evidence suggests that regular participation in physical activity helps decrease overall levels of tension, and makes one feel energized and healthy (Lai et al., 2020).

Regular physical activity is a cornerstone of chronic disease prevention and treatment. Engaging in an active lifestyle is associated with a number of important mental health outcomes. In contrast, physical inactivity is associated with poor mental health outcomes. These associations are generally robust after controlling for variables that are known to confound the activity-mental health relationship (Duncan et al, 2020).

Exercise is known to be associated with reduced risk of all-cause mortality, cardiovascular disease, stroke, and diabetes (Chekroud et al, 2018).

Physical activity (PA) may be therapeutic for people with severe mental illness (SMI) who generally have low PA and experience numerous lifestyle-related medical complications. (Stubbs et al, 2018).

Factors closely linked with SB such as social isolation, loneliness, physical inactivity, chronic physical conditions, and disability 
may play a major role in depression among middle-aged and older people. Lifestyle interventions focusing on reductions of depression among this age group need to take these factors into consideration (Vacampfort et al, 2020).

Sedentary behavior and perceived stress are both negatively associated with physical and mental health (Ashdown-Franks et al, 2020).

The largest proportion of the sedentary behavior-depression relationship was explained by mobility limitations (49.9\%), followed by impairments in sleep/energy (43.4\%), pain/discomfort $(31.1 \%)$, anxiety $(30.0 \%)$, disability $(25.6 \%)$, cognition (16.1\%), and problems with vision $(11.0 \%)$ (Stubbs et al, 2018).

The impact of sedentarism, caused by the COVID-19 home confinement, is on the neuromuscular, cardiovascular, metabolic, and endocrine systems. Just a few days of a sedentary lifestyle are sufficient to induce muscle loss, neuromuscular junction damage and fiber denervation, insulin resistance, decreased aerobic capacity, fat deposition, and low-grade systemic inflammation. Regular low/medium intensity high volume exercise, together with a $15-25 \%$ reduction in caloric intake is recommended for preserving neuromuscular, cardiovascular, metabolic, and endocrine health (Narici et al, 2020).

While of a different nature, the world has been living with another pandemic for years - physical inactivity (PI) and sedentary behavior (SB) (Pratt et al, 2020). According to the World Health Organization, $31 \%$ of individuals at the age of 15 or older are physically inactive and approximately 3.2 million deaths per year are attributed to this unhealthy lifestyle behavior.

To this point, we have discussed the potential detrimental impacts of the COVID-19 pandemic on PA behaviors and SB. It is important to note that we may also be at risk for a viscous cycle where current and potentially accelerated PI patterns and sedentary behaviors may worsen the impact of future pandemics (Hall et al, 2020).

Emerging data indicate a substantial decrease in global physical activity levels during the period of social isolation adopted worldwide to contain the spread of the coronavirus disease 2019 (COVID-19). This body of knowledge can inform evidence-based policies to be urgently implemented to counteract the impact of increased physical inactivity and sedentary behavior during the COVID-19 outbreak (Pecanha et al, 2020).

According to the World Health Organization, regular physical activity can help give our days a routine and be a way to stay in contact with family and friends. It is also good for our mental health - reducing the risk of depression, cognitive decline, and delaying the onset of dementia - and improves overall feelings.

\section{AIM OF THE STUDY}

The aim of the joint research study with Ohio State University, USA, entitled "Psychological Responses, Coping Strategies and Physical Activity during the COVID 19 Pandemic" has been proposed from the Bulgarian perspective as follows: The aim was to investigate psychological responses, coping strategies, and physical activity during the COVID - 19 lock-down period, and to examine the influence of physical activity as a coping strategy in psychological health and overall well-being during the social isolation.

\section{METHODOLOGY}

This study was conducted as an online survey realized through the Google Forms 
web survey platform (Google LLC, Mountain View, CA, United States). The online survey was anonymous and not traceable to the identity of participants, including a brief description of the study, its aim, and the declarations of anonymity and confidentiality. The study was approved by the Risk Management Committee of the Joint Training Simulation \& Analyzed Center of the Institute of ICT, Bulgarian Academy of Sciences, and it was conducted following the Declaration of Helsinki.

The survey was carried out in Bulgaria and 10 other countries (China, Malaysia, India, Turkey, Ireland, North Macedonia, Singapore, Spain, USA, and Brazil) over the period 10th of July-31st of August. The research was done among 952 Bulgarian citizens aged between 18 and $65+$. The aim was to obtain information from all different age groups. The demographic information is provided in Table 1.

To fulfill the aim of the study we used the following complex of methods:

1. Sociodemographic information (age, sex, place of residence, employment status, etc.).

2. PROMIS Item Bank v 1.0 - Emotional Distress-Anxiety \& Depression. This scale contains 10 items answered in Likert style from 1 (Never) to 5 (Always). https:// www.healthmeasures.net/search-view-measures?task $=$ Search.search

3. Herth Hope Index (HHI) (Herth, 1992). The scale contains 12 subscales based on 3 factors answered from 1 (Strongly Disagree) to 4 (Strongly Agree). The higher the score the higher the level of hope.

4. Brief Resilient Coping Scale BRCS (Sinclaire, Wallston, 2004). The short-scale contains 4 items answered on a 5 point
Likert scale from 1 (Does not describe me at all) to 5 (Describes me very well).

5. Short-form of International Physical Activity Questionnaire (IPAQ-SF) Participants reported the frequency and duration of different types of activities: vigorous (i.e. heavy lifting, performing intense aerobic exercises, using bike or treadmill); moderate (i.e. carrying light loads and bicycling at a regular pace, working out in the garden); walking activities, as well as the average time, spent sitting on a weekday, including sitting at work. Responses were converted to Metabolic Equivalent Task minutes per week (MET-min/week) according to IPAQ-SF (http://www.ipaq. ki.se).

\section{Statistical Analysis}

The statistical program SPSS 26.0 was used to process the initial data. We made descriptive analysis, correlation analysis, comparative analysis (Mann Whitney U Test, 1 way ANOVA, and Krusk al-Wallis test). Additionally, Cohen's (1988) conventions to interpret effect size were used. A reliability test with the coefficient of Cronbach's alpha was used to assess the internal consistency of the questionnaire made up of multiple Likert-type scales and items.

\section{RESULTS \& ANALYSIS}

The results obtained from the descriptive statistic regarding the sociodemographic characteristics of the participants of the survey are presented in Table 1. We analyzed the participants from different age groups, their marital status, degree of education, residency in Bulgarian cities and abroad - a total of $453 \mathrm{Fe}$ male $-47.6 \%$ and 499 Male $-52.4 \%$. 
Table 1. Demographic description

\begin{tabular}{cccc}
\hline Variables & & Frequency & Valid Percent \\
\hline City & Capital & 638 & 67.0 \\
& Other Bulgarian Cities & 249 & 26.2 \\
Gender & Abroad & 65 & 6.8 \\
& Female & 453 & 47.6 \\
Age & Male & 499 & 52.4 \\
& $18-24$ & 174 & 18.3 \\
& $25-34$ & 180 & 18.9 \\
& $35-44$ & 236 & 24.8 \\
& $45-54$ & 188 & 19.7 \\
Degree & $55-64$ & 138 & 14.5 \\
& +65 & 36 & 3.8 \\
& Secondary education & 222 & 23.3 \\
& College & 40 & 4.2 \\
& Bachelor's degree & 210 & 22.1 \\
Marital status & Master's degree & 381 & 40.0 \\
& Ph.D & 99 & 10.4 \\
& Single & 342 & 35.9 \\
& Married or in a domestic partnership & 478 & 50.2 \\
& Widowed & 7 & .7 \\
& Divorced & 102 & 10.7 \\
& Separated & 23 & 2.4 \\
\hline
\end{tabular}

Reliability test Cronbach's alpha was used item-total Correlation showed a lower correlato assess the internal consistency of the ques- tion between item 9 (I had suicidal thoughts) tionnaire made up of multiple Likert-type and the other items. If item 9 hadbeen removed, scales and items. the Cronbach's alpha could have increased to

The Anxiety Depression subscale, consist- .896 (Table 2). The scores of Anxiety \& Deing of 10 items, was found to be highly reliable pression were computed without item 9 . (Cronbach's alpha $a=.887$ ). The Corrected

Table 2. Anxiety \& Depression reliability analysis

\begin{tabular}{lcc}
\hline & $\begin{array}{c}\text { Corrected Item- } \\
\text { Total Correlation }\end{array}$ & $\begin{array}{c}\text { Cronbach's Alpha } \\
\text { if Item Deleted }\end{array}$ \\
\hline I felt fearful & .631 & .875 \\
I found it hard to focus on anything other than my anxiety & .754 & .867 \\
My worries overwhelmed me & .687 & .871 \\
I felt uneasy & .529 & .883 \\
I felt worthless & .641 & .876 \\
I felt helpless & .789 & .862 \\
I felt depressed & .722 & .868 \\
I felt hopeless & .759 & .867 \\
I had suicidal thoughts & .184 & .896 \\
COVID-19 kept me awake at night & .459 & .886 \\
\hline
\end{tabular}

The Herth Hope Index scale - 12 items, tion showed a lower and negative correlation was found to be highly reliable Cronbach's al- between items 3 and 6 ("I feel all alone" and pha $=.885$. The Corrected item-total Correla- "I feel scared about my future") and the other 
items. If items 3 and 6 had been removed the (Table 3). The scores of Anxiety \& Depression Cronbach's alpha could have increased to .911 were computed without item 9.

Table 3. Herth Hope Index - reliability analysis

\begin{tabular}{lcc}
\hline & $\begin{array}{c}\text { Corrected Item-Total } \\
\text { Correlation }\end{array}$ & $\begin{array}{c}\text { Cronbach's Alpha } \\
\text { if Item Deleted }\end{array}$ \\
\hline I have a positive outlook toward life. & .693 & .870 \\
I have short and/or long-range goals. & .692 & .869 \\
I feel all alone. & -.062 & .911 \\
I can see possibilities in the midst of difficulties. & .682 & .870 \\
I have a faith that gives me comfort. & .665 & .871 \\
I feel scared about my future. & .002 & .911 \\
I can recall happy/joyful times. & .721 & .867 \\
I have deep inner strength. & .803 & .863 \\
I am able to give and receive caring/love. & .788 & .865 \\
I have a sense of direction. & .807 & .862 \\
I believe that each day has potential. & .774 & .865 \\
I feel my life has value and worth. & .732 & .867 \\
\hline
\end{tabular}

The Brief Resilient Coping Scale BRCS, highly reliable Cronbach's alpha $=.866$, with consisting of 4 subscales, was found to be strong item correlation (Table. 4).

Table 4. BRCS reliability analysis

\begin{tabular}{lcc}
\hline & $\begin{array}{c}\text { Corrected Item- } \\
\text { Total Correla- } \\
\text { tion }\end{array}$ & $\begin{array}{c}\text { Cronbach's } \\
\text { Alpha if Item } \\
\text { Deleted }\end{array}$ \\
\hline $\begin{array}{l}\text { I look for creative ways to alter difficult situations. } \\
\text { Regardless of what happens to me, I believe I can control my } \\
\text { reaction to it. }\end{array}$ & .616 & .882 \\
$\begin{array}{l}\text { I believe I can grow in positive ways by dealing with difficult } \\
\text { situations. }\end{array}$ & .754 & .821 \\
I actively look for ways to replace the losses I encounter in life. & .719 & .794 \\
\hline
\end{tabular}

The questions of IPAQ-SF allowed to assess physical activity by providing information about the minutes per day or days per week, at any time of the day, spent doing activities during the COVID-19 Pandemic. Participants reported the frequency and duration of different types of activity: vigorous (i.e. heavy lifting, performing intense aerobic exercises, using bike or treadmill); moderate (i.e. carrying light loads and bicycling at a regular pace, working out in the garden); walking activities. Responses were converted to Metabolic Equivalent Task minutes per week (MET-min/week) though automatic scoring of the IPAQ-S. Based on the IPAQ recommendations for scoring protocol, participants of the study were classified in three groups of physical activity considering the MET-min/week of the sum of walking, moderate-intensity physical activities, and vigorous-intensity physical activities: low active ( $<600 \mathrm{MET}-$ minutes/week); moderate active ( $\geq 600 \mathrm{MET}-$ minutes/week) and high active ( $\geq 3000$ MET-minutes/week) (http://www. ipaq.ki.se). 
Table 5. Psychological responses \& Coping strategies \& Levels of PA during COVID-19 Pandemic

\begin{tabular}{lccc}
\hline \multicolumn{1}{c}{ Variables } & & Frequency & Valid Percent \\
\hline Anxiety \& Depression & Low & 373 & 39.2 \\
& Average & 265 & 27.8 \\
HHI & High & 314 & 33.0 \\
& Low & 343 & 36.0 \\
\multirow{4}{*}{ BRIC } & Average & 309 & 32.5 \\
& High & 300 & 31.5 \\
& Low & 144 & 15.1 \\
MET & Average & 527 & 55.4 \\
& High & 281 & 29.5 \\
\multirow{4}{*}{ Levels of PA } & Low & 179 & 19.2 \\
& Average & 355 & 38.1 \\
& High & 397 & 42.6 \\
& Increased & 83 & 8.8 \\
& Decreased & 409 & 43.4 \\
& Almost the same & 365 & 38.7 \\
\hline
\end{tabular}

With the purpose to evaluate the difference between female and male participants regarding their psychological responses (anxiety and depression, hope and coping strategies) during the COVID-19 pandemic we used Mann Whitney U Test. Additionally we computed Cohen's coefficient to interpret effect size. The total number of respondents was $\mathrm{N}=952$, Female $\mathrm{N}=$ 453, Male $N=499$. The test revealed significant differences in the levels of anxiety (Female $\mathrm{M}=$ 1.62 vs Male $\mathrm{M}=1.35, p<0.0001$, Cohen's $d$ $=$.324). HHI (Hert Hope Index) revealed moderately significant differences (Female $\mathrm{M}=3.29$ vs Male $\mathrm{M}=3.53, p<0.0001$, Cohen's $d=.25$ ). Regarding BRIC (Brief Resilience Index Cop- ing) and gender, the differences were marginally significant (Female $\mathrm{M}=3.95$ vs Male $\mathrm{M}=$ 4.02, $p<0.01$, Cohen's $d=.09$ ).

We analyzed the physical activities during the lock-down performed by men and women. The Mann Whitney U Test showed insignificant differences between the groups $(\mathrm{N}=931$, Female $=448$, Male $=483,3442$ vs 3471, N.s., Cohen's $d=.04)$. The analysis revealed an insignificant difference between the groups regarding the levels of vigorous and moderate levels of physical activities. Regarding walking activities we found slight differences in the observed groups $(\mathrm{N}=885$, Female $=430$, Male $=455,1537$ vs 1197, $p<0.0001$, Cohen's $d=.13$ ) (Table 6).

Table 6. Comparative analysis along with the factor gender

\begin{tabular}{ccccc}
\hline Variables & Female & Male & Sig. & Cohen's d \\
\hline Anxiety & 1.62 & 1.35 & .0001 & .32 \\
BRIC & 3.95 & 4.02 & .02 & .09 \\
HHI & 3.29 & 3.53 & .0001 & .25 \\
MET & 3442 & 3471 & N.s. & .04 \\
Vigorous & 1306 & 1641 & N.s. & .03 \\
Moderate & 749 & 871 & N.s. & .04 \\
Walk & 1537 & 1197 & .0001 & .13 \\
\hline
\end{tabular}

\section{Hypothesis Testing}

The Kruskal Wallis test rejected the null hypothesis stating that the distribution of levels of anxiety was the same in the observed age groups $\chi^{2}(5, \mathrm{~N}=952)=38.48, p<.0001$. The pairwise comparison test revealed significant differences between group 1(18-24) and the 3 of the observed 6 groups. The effect size was measured 
with the Mann Whitney test. A significant difference was revealed with the group $4(45-54)(\mathrm{N}$ $=362,1=174,4=188,1.66$ vs $1.41, p<0.0001$, Cohen's $d=.27)$, group $2(25-34)(\mathrm{N}=354, p<$ 0.0001 , Cohen's $d=.24)$, and group $3(35-44)(\mathrm{N}$ $=410, p<0.0001$, Cohen's $d=.24)$. The analysis revealed high levels of anxiety and depression among the youngest respondents in comparison with those among the groups aged 25 to 54 .

The comparative analysis of the HHT (Herth Hope Index) along the factor age revealed significant differences $\chi^{2}(5, \mathrm{~N}=952)$ $=48.67, p<.0001$ between the group $6(+65)$ and the other 5 observed groups. The biggest difference was found in the comparison with group $4(45-54)(\mathrm{N}=224,4=188,6=36$, 3.1 vs.3.5, $p<0.0001$, Cohen's $d=.28$ ).

The Kruskal Wallis test rejected the null hypothesis stating that the distribution of mean scores of BRIC was the same in the observed age groups $\chi^{2}(5, \mathrm{~N}=952)=23.75, p<.0001$. The analysis revealed significant differences between group $6(65+)$ and the other 5 groups.

Analyzing the levels of physical activities among the observed groups with the Kruskal
Wallis test, we rejected the null hypothesis stating that the distribution of MET was the same across the different age groups $\chi^{2}(5, \mathrm{~N}=952)$ $=49.16, p<0.0001$. The pairwise comparison revealed a statistical difference between group $6(65+)$ and the other 5 observed groups. But the analysis showed a negative trend in the comparison of first two groups 18-24 and 2434. $(\mathrm{N}=354,1(18-24)=174,2=180,3314$ vs $3803, p<0.05$, Cohen's $d=.17)$. Regarding the founded difference we analyzed the levels of vigorous physical activities between the same groups $(\mathrm{N}=333,18-24=163,25-34=170$, 1306 vs $1641, p<0.0001$, Cohen's $d=.37)$ and the levels of moderate physical activities (607 vs $1076, p<0.001$, Cohen's $d=.18$ ).

The comparative analysis of the different kinds of physical activities along factor age revealed significant differences between group 6 $(+65)$ and the other groups. The analysis showed that the adults $65+$ had the lowest levels of all physical activities, but also revealed the lowest levels in vigorous and moderate activities in the groups of youngest respondents in comparison with those of the other age groups (Table 7).

Table 7. Comparative analysis along with the factor age

\begin{tabular}{cccc}
\hline Variable & Asymp. Sig. & df & Chi-Squared \\
\hline Anxiety & .000 & 5 & 49.161 \\
BRIC & .000 & 5 & 23.746 \\
HHI & .000 & 5 & 38.487 \\
MET & .000 & 5 & 48.672 \\
Vigorous & .000 & 5 & 83.679 \\
Moderate & .000 & 5 & 55.011 \\
Walk & .000 & 5 & 73.417 \\
\hline
\end{tabular}

a. Kruskal Wallis Test;

b. Grouping Variable: Age

The aim of that study was to explore the impact of the change of the levels of physical activity during the lock-down period, among mental health and wellbeing. The Kruskal Wallis test rejected the null hypothesis stating that the distribution of mean scores of BRIC was the same in the observed groups $\chi^{2}(3, \mathrm{~N}=$ $952)=30.80, p<.0001$. The analysis showed a significant difference between the groups with increased and decreased levels of physical activities $(\mathrm{N}=492$, Increased $=83$, Decreased $=$ $409,4.2$ vs 3.9, $p<0.0001$, Cohen's $d=.20$ ).

The comparative analysis of the HHT (Herth Hope Index) along the factor age also revealed differences $\chi^{2}(3, \mathrm{~N}=942)=8.60$, $p<.03$ between the observed groups. The analysis 
presented slight differences between the groups with Increased and Decreased levels of physical activity (3.9 vs 3.3, $p<0.0001$, Cohen's $d=.12$ ).

Table 8. Comparative analysis along the factor levels of physical activity during the lock-down period

\begin{tabular}{cccc}
\hline Variable & Asymp. Sig. & df & Chi-Squared \\
\hline Anxiety & N.s. & 3 & 7.248 \\
BRIC & .000 & 3 & 30.802 \\
HHI & .035 & 3 & 8.606 \\
\hline
\end{tabular}

a. Kruskal Wallis Test; $\quad$ b. Grouping Variable: PA levels

The open-ended question "During the lock- ation. After mentioning "friends", which presents down period, what are the top five things you did some of the cultural features of the Bulgarian popto cope with the difficulties in order to maintain ulation, the respondednts reported "Sport" as the positivity?" was summarized to present the most second important thing as a coping strategy with used things for coping with the extraordinary situ- the consequences of social isolation (Table 9).

Table 9. Responses to the question "During the lockdown period, what are the top five things you did to cope with the difficulties in order to maintain positivity?"

\begin{tabular}{|c|c|c|c|c|c|}
\hline & & & \multicolumn{2}{|c|}{ Responses } & \multirow{2}{*}{ Percent of Cases } \\
\hline & & & $\mathbf{N}$ & Percent & \\
\hline \multirow[t]{29}{*}{ Coping } & sport & & 138 & $8.1 \%$ & $22.7 \%$ \\
\hline & music & & 63 & $3.7 \%$ & $10.4 \%$ \\
\hline & friends & & 201 & $11.9 \%$ & $33.1 \%$ \\
\hline & family & & 105 & $6.2 \%$ & $17.3 \%$ \\
\hline & communication & & 91 & $5.4 \%$ & $15.0 \%$ \\
\hline & dances & & 16 & $0.9 \%$ & $2.6 \%$ \\
\hline & care & & 72 & $4.2 \%$ & $11.9 \%$ \\
\hline & books & & 123 & $7.3 \%$ & $20.3 \%$ \\
\hline & films & & 65 & $3.8 \%$ & $10.7 \%$ \\
\hline & meditation & & 39 & $2.3 \%$ & $6.4 \%$ \\
\hline & learning & & 40 & $2.4 \%$ & $6.6 \%$ \\
\hline & teaching & & 7 & $0.4 \%$ & $1.2 \%$ \\
\hline & work & & 79 & $4.7 \%$ & $13.0 \%$ \\
\hline & hobby & & 61 & $3.6 \%$ & $10.0 \%$ \\
\hline & science & & 32 & $1.9 \%$ & $5.3 \%$ \\
\hline & fait & & 117 & $6.9 \%$ & $19.3 \%$ \\
\hline & painting & & 13 & $0.8 \%$ & $2.1 \%$ \\
\hline & love & & 24 & $1.4 \%$ & $4.0 \%$ \\
\hline & will & & 56 & $3.3 \%$ & $9.2 \%$ \\
\hline & calmness & & 57 & $3.4 \%$ & $9.4 \%$ \\
\hline & courage & & 20 & $1.2 \%$ & $3.3 \%$ \\
\hline & walking & & 30 & $1.8 \%$ & $4.9 \%$ \\
\hline & action & & 31 & $1.8 \%$ & $5.1 \%$ \\
\hline & cooking & & 53 & $3.1 \%$ & $8.7 \%$ \\
\hline & persistence & & 33 & $1.9 \%$ & $5.4 \%$ \\
\hline & wellbeing & & 35 & $2.1 \%$ & $5.8 \%$ \\
\hline & positivism & & 36 & $2.1 \%$ & $5.9 \%$ \\
\hline & others & & 59 & $3.5 \%$ & $9.7 \%$ \\
\hline & & Total & 1696 & $100.0 \%$ & $279.4 \%$ \\
\hline
\end{tabular}




\section{DISCUSSION}

The coronavirus disease 2019 (COVID-19) pandemic is having a profound effect on all aspects of society, including mental health and physical health. In the midst of this COVID-19 crisis, the discussion is open about what we need to be preparing as citizens in an interconnected world against the incoming second wave of pandemic and the threats of any kind.

The unprecedented disruption of the normal life of the citizens around the world was a big challenge for the whole society, the governments, the public sector, but also for the scientists from different areas. Moreover, science has to find reliable means - drugs and vaccines against COVID - 19, which requires a lot of resources and time. The mental and physical health of the whole population during the era of a pandemic have to be ensured.

The main goal of the analysis was to examine the influence of physical activity as a coping strategy in psychological health and overall well-being. Regarding this perspective, we have summarized the following tendencies:

$>43.4 \%$ of the respondents have decreased levels of physical activities, besides $8.8 \%$ answered increased;

The most affected groups of decreased levels of physical activities are the group $(65+)$ followed by the youngest respondents (18-24);

$>$ The group of the youngest has the highest levels of anxiety and depression;

According to the change of the levels of physical activity during the lock-down period the respondents with the increased levels of PA presented significantly higher levels of coping with the pandemic situation in comparison with the persons with decreased levels of PA;

"Sport" was answered as the second important tool as a coping strategy with the consequences of social isolation.
The lack of specific drugs and vaccines, which provides anxiety about the uncertainty of virus development, the lock-down orders, and the increased number of confirmed cases and deaths, could lead to negative health consequences long after overcoming the pandemic situation. The big issue is how to create coping strategies applicable to the whole society and how to encourage the groups with lower levels of physical activity to do exercises. One of the high impacted group is 18-24 years most of them are pupils and students, which requires educational institutions to introduce new educational programs in order to increase physical activity and improve mental health.

The enhanced levels of physical activity not only could support physical and mental health but also could be used in the prevention of infections and other non-communicable diseases. Although behavioural therapy can help them to combat anxiety with the use of relaxation techniques and prevent depression onset by altering the schedule of their routine activities, cognitive behavioural therapy CBT can mitigate maladaptive coping behaviours such as avoidance, antagonistic confrontation and self-blame by enhancing their ability to manage stress (Ho et al., 2020).

\section{LIMITATIONS}

During the era of COVID - 19, pandemic, and unprecedented lock-down in the countries around the world maintaining physical and mental health becomes more important than ever. The global impact of the pandemic situation leads to an urgent need to create strategies for combating such pandemic. The long-term goal of the study is to examine the differences in psychological responses, coping strategies, and physical activity across countries and to reveal the reliable coping strategies for creating a sustainable future for our society. 


\section{REFERENCES}

Ashdown-Franks, G., Koyanagi, A., Vancampfort, D., Smith, L., Firth, J., Schuch, F., Veronese, N., \& Stubbs, B. (2018). Sedentary behavior and perceived stress among adults aged $\geq 50$ years in six low- and middle-income countries. Maturitas, 116, 100-107. https:// doi.org/10.1016/j.maturitas.2018.08.005

Chekroud, S. R., Gueorguieva, R., Zheutlin, A. B., Paulus, M., Krumholz, H. M., Krystal, J. H., \& Chekroud, A. M. (2018). Association between physical exercise and mental health in 1,2 million individuals in the USA between 2011 and 2015: a cross-sectional study. The lancet. Psychiatry, 5(9), 739-746. https://doi. org/10.1016/S2215-0366(18)30227-X

Duncan, G. E., Avery, A. R., Seto, E., \& Tsang, S. (2020). Perceived change in physical activity levels and mental health during COVID-19: Findings among adult twin pairs. PloS one, 15(8), e0237695. https:/doi. org/10.1371/journal.pone.0237695

Hall, G., Laddu, D. R., Phillips, S. A., Lavie, C. J., \& Arena, R. (2020). A tale of two pandemics: How will COVID-19 and global trends in physical inactivity and sedentary behavior affect one another?. Progress in cardiovascular diseases, S0033-0620(20)300773. Advance online publication. https://doi. org/10.1016/j.pcad.2020.04.005

Herth K. (1992). Abbreviated instrument to measure hope: development and psychometric evaluat ion. Journal of advanced nursing, 17(10), 1251-1259. https://doi. org/10.1111/j.1365-2648.1992.tb01843.x

Ho, C. S., Chee, C. Y., \& Ho, R. C. (2020). Mental Health Strategies to Combat the Psychological Impact of COVID-19 Beyond Paranoia and Panic. Annals of the Academy of Medicine, Singapore, 49(3), 155-160.

Iancheva, T., Rogaleva, L., García-Mas, A., Olmedilla, A. (2020). Perfectionism, mood states, and coping strategies of sports students from Bulgaria and Russia during the pandemic COVID-19. Journal of Applied Sports Sciences 2020, Vol. 1, pp. 22-38. ISSN 2535-0145. https://doi.org/10.37393/JASS.2020.01.2

International Physical Activity Questionnaire (IPAQ) (n.d). http://www.ipaq.ki.se, Retrived September 30, 2020

Kruskal, W.H., \& Wallis, W.A. (1952). Use Of Ranks In One Criterion Variance Analysis. Journal Of The American Statistical Association, 47,583-621.Available at: http://www. sciepub.com/reference/34577 [Retrieved October 5, 2020].

Lai, J., Ma, S., Wang, Y., Cai, Z., Hu, J., Wei, N., Wu, J., Du, H., Chen, T., Li, R., Tan, H., Kang, L., Yao, L., Huang, M., Wang, H., Wang, G., Liu, Z., \& Hu, S. (2020). Factors Associated With Mental Health Outcomes Among Health Care Workers Exposed to Coronavirus Disease 2019. JAMA network open, 3(3), e203976. https://doi.org/10.1001/ jamanetworkopen.2020.3976

Lim, G. Y., Tam, W. W., Lu, Y., Ho, C. S., Zhang, M. W., \& Ho, R. C. (2018). Prevalence of Depression in the Community from 30 Countries between 1994 and 2014. Scientific reports, 8(1), 2861. https://doi.org/10.1038/ s41598-018-21243-x

Mann, H.B. and Whitney, D.R. (1947). On a Test of Whether One of Two Random Variables Is Stochastically Larger than the Other. Annals of Mathematical Statistics, 18, 50-60. http://dx.doi.org/10.1214/aoms/1177730491

Maugeri, G., Castrogiovanni, P., Battaglia, G., Pippi, R., D’Agata, V., Palma, A., Di Rosa, M., \& Musumeci, G. (2020). The impact of physical activity on psychological health during the Covid-19 pandemic in Italy. Heliyon, 6(6), e04315. https://doi.org/10.1016/j. heliyon.2020.e04315

Narici, M., De Vito, G., Franchi, M., Paoli, A., Moro, T., Marcolin, G., Grassi, B., Baldassarre, G., Zuccarelli, L., Biolo, G., di Girola- 
mo, F. G., Fiotti, N., Dela, F., Greenhaff, P., \& Maganaris, C. (2020). Impact of sedentarism due to the COVID-19 home confinement on neuromuscular, cardiovascular, and metabolic health: Physiological and pathophysiological implications and recommendations for physical and nutritional countermeasures. European journal of sports science, 1-22. https://doi.org/ 10.1080/17461391.2020.1761076

Niti, M., Ng, T. P., Kua, E. H., Ho, R. C., \& Tan, C. H. (2007). Depression and chronic medical illnesses in Asian older adults: the role of subjective health and functional status. International journal of geriatric psychiatry, 22(11), 1087-1094. https://doi.org/10.1002/ gps. 1789

Peçanha, T., Goessler, K. F., Roschel, H., \& Gualano, B. (2020). Social isolation during the COVID-19 pandemic can increase physical inactivity and the global burden of cardiovascular disease. American journal of physiology. Heart and circulatory physiology, 318(6), H1441-H1446. https://doi.org/10.1152/ajpheart.00268.2020

Pratt, M., Ramirez Varela, A., Salvo, D., Kohl Iii, H. W., \& Ding, D. (2020). Attacking the pandemic of physical inactivity: what is holding us back? British journal of sports medicine, 54(13), 760-762. https://doi. org/10.1136/bjsports-2019-101392

Sarris, J., O’Neil, A., Coulson, C. E., Schweitzer, I., \& Berk, M. (2014). Lifestyle medicine for depression. BMC psychiatry, 14, 107. https://doi.org/10.1186/1471-244X-14-107

Sinclair, V. G., \& Wallston, K. A. (2004). The development and psychometric evaluation of the Brief Resilient Coping Scale. Assessment, 11(1), 94-101. https://doi. org/10.1177/1073191103258144

Stubbs, B., Vancampfort, D., Firth, J., Schuch, F. B., Hallgren, M., Smith, L., Gardner, B., Kahl, K. G., Veronese, N., Solmi, M., Carvalho, A. F., \& Koyanagi, A. (2018). Re- lationship between sedentary behavior and depression: A mediation analysis of influential factors across the lifespan among 42,469 people in low- and middle-income countries. Journal of affective disorders, 229, 231-238. https://doi.org/10.1016/j.jad.2017.12.104

Stubbs, B., Vancampfort, D., Hallgren, M., Firth, J., Veronese, N., Solmi, M., Brand, S., Cordes, J., Malchow, B., Gerber, M., Schmitt, A., Correll, C. U., De Hert, M., Gaughran, F., Schneider, F., Kinnafick, F., Falkai, P., Möller, H. J., \& Kahl, K. G. (2018). EPA guidance on physical activity as a treatment for severe mental illness: a meta-review of the evidence and Position Statement from the European Psychiatric Association (EPA), supported by the International Organization of Physical Therapists in Mental Health (IOPTMH). European psychiatry: the journal of the Association of European Psychiatrists, 54, 124-144. https:// doi.org/10.1016/j.eurpsy.2018.07.004

Tee, M. L., Tee, C.A., Anlacan, J.P., Aligam, K., Reyes, P., Kuruchittham, V., \& Ho, R. C. (2020). Psychological impact of COVID-19 pandemic in the Philippines. Journal of affective disorders, 277, 379-391. https://doi. org/10.1016/j.jad.2020.08.043

Tran, B. X., Nguyen, H. T., Le, H. T., Latkin, C. A., Pham, H. Q., Vu, L. G., Le, X., Nguyen, T. T., Pham, Q. T., Ta, N., Nguyen, Q. T., Ho, C., \& Ho, R. (2020). Impact of COVID-19 on Economic Well-Being and Quality of Life of the Vietnamese During the National Social Distancing. Frontiers in psychology, 11, 565153. https://doi.org/10.3389/ fpsyg. 2020.565153

Vancampfort, D., Hallgren, M., Schuch, F., Stubbs, B., Smith, L., Rosenbaum, S., Firth, J., Van Damme, T., \& Koyanagi, A. (2020). Sedentary behavior and depression among community-dwelling adults aged $\geq 50$ years: Results from the Irish longitudinal study on Ageing. Journal of affective disorders, 262, 389-396. 
https://doi.org/10.1016/j.jad.2019.11.066

Wang, C., Pan, R., Wan, X., Tan, Y., Xu, L., McIntyre, R. S., Choo, F. N., Tran, B., Ho, R., Sharma, V. K., \& Ho, C. (2020). A longitudinal study on the mental health of general population during the COVID-19 epidemic in China. Brain, behavior, and immunity, 87, 40-48. https://doi.org/10.1016/j.bbi.2020.04.028

Wegner, M., Helmich, I., Machado, S., Nardi, A. E., Arias-Carrion, O., \& Budde, H. (2014). Effects of exercise on anxiety and depression disorders: a review of meta-analyses and neurobiological mechanisms. CNS \& neurological disorders drug targets, 13(6), 10021014. https://doi.org/10.2174/1871527313666 140612102841

WorldHealthOrganization.(n.d.).\#HealthyAtHome - Physical activity. World Health Organization. https://www.who.int/news-room/ campaigns/connecting-the-world-to-combat-coronavirus/healthyathome/healthyathome---physical-activity. Retrived September 28,2020

Corresponding author:

Zornitza Mladenova, PhD

The Foundation for Global Community Health E-mail: z.mladenovaz@gmail.com 